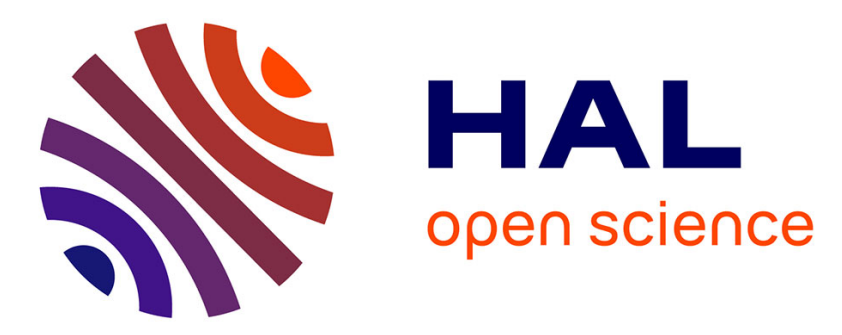

\title{
The application of smartphone technology to economic and environmental analysis of building energy conservation strategies
}

\author{
Patrick Leslie, Joshua Pearce, Rob Harrap, Sylvie Daniel
}

\section{To cite this version:}

Patrick Leslie, Joshua Pearce, Rob Harrap, Sylvie Daniel. The application of smartphone technology to economic and environmental analysis of building energy conservation strategies. International Journal of Sustainable Energy, 2012, 31 (5), pp.295-311. 10.1080/1478646X.2011.578746 . hal-02120460

\author{
HAL Id: hal-02120460 \\ https://hal.science/hal-02120460
}

Submitted on 6 May 2019

HAL is a multi-disciplinary open access archive for the deposit and dissemination of scientific research documents, whether they are published or not. The documents may come from teaching and research institutions in France or abroad, or from public or private research centers.
L'archive ouverte pluridisciplinaire HAL, est destinée au dépôt et à la diffusion de documents scientifiques de niveau recherche, publiés ou non, émanant des établissements d'enseignement et de recherche français ou étrangers, des laboratoires publics ou privés. 
P. Leslie, J. M. Pearce, R. Harrap, S. Daniel, “The application of smartphone technology to economic and environmental analysis of building energy conservation strategies”, International Journal of Sustainable Energy 31(5), pp. 295-311 (2012).

DOI: $\underline{\text { http://dx.doi.org/10.1080/1478646X.2011.578746 }}$

\title{
The application of smartphone technology to economic and environmental analysis of building energy conservation strategies
}

\author{
Patrick Leslie $^{\mathrm{a}}$, Joshua M. Pearce*a, Rob Harrap ${ }^{\mathrm{b}}$, Sylvie Daniel ${ }^{\mathrm{c}}$ \\ ${ }^{a}$ Department of Mechanical and Materials Engineering, Queens University, Kingston, Canada \\ ${ }^{b}$ Department of Geological Sciences \& Geological Engineering, Queen’s University, Kingston, Canada \\ ${ }^{c}$ Département des Sciences Géomatiques, Université Laval, Quebec, Canada
}

\begin{abstract}
This paper investigates the use of smartphone technology as a tool to implement building energy audit programs to increase energy conservation measure (ECM) uptake and concomitant environmental and economic benefits. The smartphone audit analyzed provides a energy audit platform with: i) quasi-real time analysis, ii) continuous user engagement, iii) geospatial customization, iv) additional ECMs, v) ECM ranking and user education, and vi) the ability to constantly evolve. A case study of 157,000 homes in Southeastern Ontario shows that 55 years is needed to complete energy audits for all dwellings in the region following a traditional energy audit model. However, the results of the smartphone based audit program accelerates this in both terms of audits completed and cumulative carbon dioxide savings over a sensitivity range of audit effectivenesses. It is concluded that an advanced and expanded home energy auditing program that uses smartphone technology could provide significant economic and environmental benefits.
\end{abstract}

Keywords: energy audit; energy efficiency; smartphone; energy conservation measures; sustainable architecture; residential buildings

\section{Introduction}

Global climate change due to anthropogenic carbon dioxide $\left(\mathrm{CO}_{2}\right)$ emissions is now supported by an overwhelming quantity of scientific evidence and is widely viewed as an urgent global issue (IPCC 2007, Stern 2007). Although climate change is affecting regions of many countries, in Canada the negative effects of climate change are already present throughout the entire country and will increase climate related risk within communities, infrastructure and ecosystems (NRC 2007a). Within Canada, one of the primary contributors to $\mathrm{CO}_{2}$ emissions comes from residential buildings. According to Natural Resources Canada, residential buildings account for 16.3\% of total energy use in Canada (NRC 2009a). Much of these emissions could be mitigated as studies have found that profitable energy conservation measures (ECMs) in buildings have the potential to save on average $47 \%$ on targeted devices and 23\% of the utility bill baseline (Office of Technology Assessment 1979, Osborn et al. 2002). One method used in both Canada and the U.S., to promote the use of these ECMs is to subsidize home energy audits so that they are more affordable for consumers (Government of Alberta 2009, Ontario Home Energy 2010).

Current home energy audits consist of trained professionals traveling to individual residences to obtain an estimate of the current site conditions and energy use in order to suggest where building owners are able to reduce their energy consumption. These widely available home energy audits, while comprehensive in evaluating heating and cooling needs, neglect many other energy consuming devices in the home. Appliances other then those used for heating and cooling are generally bypassed, with the

*Corresponding author. Email: pearce@me.queensu.ca 
exception of some audits done directly by Energy Star who often suggest moving to Energy Star approved appliances (U.S. EPA and U.S. DOE 2009). As well, some auditors may record the number and type of toilets if an incentive for low flow units exists within the area. Regardless, the vast majority of homes in North America have not undergone an audit of any type. This limits the homeowner's ability to recognize where energy savings could be achieved through relatively simple upgrades.

Throughout a home, many other areas exist for potential energy savings, which are within the technical scope of the average consumer. For example a lighting systems ECM that requires switching from incandescent light bulbs to more energy efficient bulbs (compact fluorescent light bulbs or light emitting diodes) is within the ability of the average home user to complete and would contribute significantly to energy consumption reductions (Prose and Wortmann 1991, Pearce and Russill 2005). Whether the goal of the consumer is to reduce carbon footprint or simply to save money in the long run, as long as the consumer can recognize the potential savings, they may be motivated to act. The issue is situational awareness of what to look at, what factors to consider, and what actions are possible. Often the consumer lacks not the ability to make the changes, but the ability to recognize which changes are possible and which have the largest potential to reduce energy use.

One potential approach to providing ECMs to the average consumer is through the use of software tools that guide decision-making. Although such tools could be used via a desktop computer, this poses a problem in that the tool cannot be moved around while an audit is being done; laptops are slightly less cumbersome, but still inconvenient. Such tools are, however, potentially deployable using the capabilities of modern smartphones. Smartphones are cellular phones that combine, but are not limited to; voice, Internet connectivity, and the ability to add local or Web-based applications. Smartphone technology has advanced rapidly in the past decade and continues to see unprecedented growth in user base, with smartphones making up 20\% of all cellular phones sold in North America in 2008, a 69\% increase from the same time the year before (Stevens and Pettey 2009, Gartner 2009). The global market sales of smartphones in 2009 was 172 million units (Pettey and Tudor 2010). These phones are now often equipped with features such as cameras, GPS systems, accelerometers, compasses, high end processors, high speed Internet connections and intuitive user interfaces. Programming such a device to leverage these capabilities to support on-site energy audits by the average consumer will provide new opportunities for home energy audits. Such a device can record existing conditions, use directed questions to guide more detailed evaluation, provide instant feedback, and even provide an estimate of projected energy savings for a specific upgrade, or aggregate of individual upgrades, in real time as the audit is performed.

This paper explores the potential for use of smartphone technology in home energy audits. Combining built-in educational material to guide audit data collection and retrofit suggestions with the ability to deliver advanced economic projections provides significant individualized decision support in the hands of users. Such smartphone tools both inform users and help guide them to environmentallyand economically-sound decisions about ECMs. First, a theoretical model of the smartphone program and the features that it would contain is developed, including features that are beyond the scope of current energy audits. Next, the potential energy savings of the current home energy audit model are quantified using an existing non-profit agency as a case study. The potential capabilities of these two models are then evaluated using a diffusion of innovation model and energy savings projections and a sensitivity analysis is provided for audit effectiveness. 
P. Leslie, J. M. Pearce, R. Harrap, S. Daniel, “The application of smartphone technology to economic and environmental analysis of building energy conservation strategies”, International Journal of Sustainable Energy 31(5), pp. 295-311 (2012).

DOI: http://dx.doi.org/10.1080/1478646X.2011.578746

\section{Potential of Smartphone Applications in Energy Conservation}

Recent work that focuses on the fundamental differences between smartphone-based and Internet applications, and how these might enhance sustainable strategies (Pitt et al., in press) suggests that UCommerce, or Über-commerce, be used as a theoretical framework (Watson et al., 2002). The characteristics of network ubiquity, universality, uniqueness, and unison developed by U- Commerce enable the decision support systems running on smartphones to have a large impact on energy conservation on a broad scale. Smartphones have the potential to assist with some aspects of ECM use and to automate others; such tools also may open up entirely new evaluation methods that are simply impractical without significant sensing and computing power. Smartphone based decision support tools offer a number of capabilities. First, a tool might make use of the sensors in the phone, including camera (to take pictures for including in a report and to identify equipment, as a crude light meter and measuring device), orientation sensing (inclinometer for quantifying roof planes for solar retrofits), compass, and GPS, to sense the general character of the physical environment (e.g. the physical characteristics of the building) or take spatial measurements. Additional sensors and external instrumentation (IR cameras, flow sensors, etc.) could be coupled to the smartphone through existing protocols such as Bluetooth, which is a short range wireless connectivity standard. Second, the tool might guide the user through a sequence of data collection steps, similar to how wizard tools in desktop software support the use of advanced features or installation of software. By posing a sequence of steps as simpler decisions with supporting notes about what the intent is and what the scope of the decisions are, a user can be led through a process that would otherwise be too daunting. The mobility of the device allows going through the steps physically on site, providing some context and tangible representation of the actions. The goal of such an interface is to enable data collection to be as painless as possible for the consumer (e.g. the user identifies the room type, then works through a scripted 'workflow wizard' that asks relevant questions and fills in details while checking for consistency). Third, the device can use local or remote data, in combination with the sensed or entered information, to compute energy and monetary savings over time. Smartphones can be used dynamically to look up properties of objects, e.g. by scanning bar codes or serial numbers. The ability to do each of these tasks improves as phone technology upgrades - new sensors, better interfaces, and faster processors only increase what can be done on the phone.

One of the main advantages of the smartphone platform as an ECM tool is its mobility. It allows users to collect information about the home indoors as well as outdoors. With the embedded sensors (ex. accelerometers, compass, gyroscope), the smartphone can be used as a modeling and measuring tool. In (Thomas et al. 2010), a prototype dedicated to 3D modeling using an iPhone 3G is described. The application is specifically targeting the public at large and context where no specific preparation is required to have the prototype work. Such an approach could be used for an energy audit where the house dimensions, number of planar surfaces or roof sloping sides could be included in the energy building model. Given the smartphone's Internet connection, a remote geospatial database could be accessed to get specific information about the house that would help tune the local measurements. Thus, the house footprint could be retrieved from cadastral database and help fine tune the 3D modeling of the building.

New interactive and immersive interfaces could also contribute to the engagement of users in performing the energy audit of their house including mobile augmented reality (MAR). Augmented reality is an emerging technology by which a user's view of the real world is augmented with additional information from a computer model. An augmented reality application is said to be mobile if the user is 
his own avatar and his position in the synthetic world follows his displacements in the real environment (Broll et al. 2008). The first MAR applications aimed at facilitating repair of complex machinery by superimposing maps or instructions directly on the actual equipment (Azuma 1997). Instructions are easier to understand when being situated and even animated, displaying step by step the task that need to be done as you are doing it. Such an approach may be useful to the energy audit. There are still issues (e.g. accurate registration of the virtual graphics on the real world; computer vision processing on smartphones is still limited by computational power) to solve before being able to use MAR interface in an energy audit, but the recent progresses and strong emergence of augmented reality research work make it possible to envision it in the near future.

A versatile, easy to use program designed to run on smartphones, which could be widely distributed, could end up increasing the effectiveness of government-sponsored energy efficiency programs and provide the ability to instantly respond to changing conditions within the home retrofitting market. Fast Internet connections and the technical evolution of modern smartphones provide a energy audit platform with additional features including: i) quasi-real time analysis, ii) dynamic information sharing, iii) geospatial customization, iv) an enhanced catalog of ECMs, v) ECM ranking and user education, and vi) the ability to constantly evolve. An example of the value that smartphone technology will provide for energy audits is the ability to use the camera and a reference object to determine the size of heat loss surfaces in the home like windows (Kemans 2010). This is a fundamental advantage of using smartphone technology over a simple web interface. As the energy audit program is software based and only existing hardware abilities are considered, the majority of the program costs will be in the upfront development. Distribution and infiltration of the market have relatively low cost as the software can be distributed freely following FLOSS (free/libre/open source software) or free-ware models. FLOSS software is licensed to grant the right of users to use, study, change, and improve its design through the availability of its source code. This open source approach has gained both momentum and adoption as the potential benefits have been increasingly recognized and is exemplified in the success of software like the Firefox web browser, the Apache web server, and the Linux operating systems (DiBona et al. 1999, Lee et al. 2009). As is shown in Section 4, the ability of an audit program to spread to a wide group dictates the overall energy savings.

Traditional energy audits focus on heating systems and building envelopes/insulation. The technical abilities of current smartphones enable several other ECMs, which include: i) lighting, ii) water conservation and iii) appliance analysis. A lighting ECM could enable all fixtures to be input into the program and will output recommendations for lamp replacements (detailed in the example ECM below). The combination of dynamic information sharing and geospatial awareness will give the program a unique ability to acquire accurate pricing and even suggest local retailers. A collection of water conservation ECMs will be able to evaluate the primary uses of water and make suggestions as to ways to reduce energy and water consumption at sinks, showers, toilets, irrigation systems, water heaters and washing machines. A collection of ECMs can be developed to compare appliances to a database and return the benefits of switching to an alternative appliance. A host of appliance ECMs could make use of camera phones to recognize types and models of appliances, gather information from Internet databases and recommend possible sources of energy savings based on rigorous economics and environmental considerations. Some augmented reality applications could then retrieve information about these domains and display additional information superimposed on reality once the recognition is completed (e.g. what a high-efficiency gas furnace would look like after replacing a low-efficiency oil furnace). The camera recognition can incorporate a number of different existing software solutions including optical character recognition, bar code/QR code, or data matrix reading or object recognition software (Google 2010a, Occipital 2010, Amazon 2010). 
P. Leslie, J. M. Pearce, R. Harrap, S. Daniel, “The application of smartphone technology to economic and environmental analysis of building energy conservation strategies”, International Journal of Sustainable Energy 31(5), pp. 295-311 (2012).

DOI: http://dx.doi.org/10.1080/1478646X.2011.578746

Being that image-based recognition technology will require more challenging programming than the remaining segments of the software package, the first generation of smart phone audit applications will probably use direct serial and model number input rather than OCR or product image recognition. Finally, the product information can be used to query a database for technical specifications and compare models to energy efficient models in a database such as the Energy Star database (Energy Star 2010b). Some of these more advanced functions will require extensive software programming and integration of third party applications. Therefore, they will be dedicated to the next models of smartphones and to the second generation of audit applications. In summary, a potential feature list comparing the current audit system, existing technology and future applications to be built for smartphone (x signifies positive response) is shown in Table 1.

\subsection{Software Experience}

Unlike traditional audits, which first collect data and then process it by trained professionals off site, in a smartphone audit the calculations have the potential to be performed in real time at the site on the device itself by inexperienced users. As a non-professional will be performing the audit, the interface with the user will need to be intuitive, seamless, and easy to use. To assist this in occurring the background energy calculations involved in a smartphone assisted audit need to be open and transparent in order to ensure trust in the user in the absence of a professional auditor (Corbett et al. 2010). Such calculations can be drawn from trusted, government sponsored programs and information databases like RetScreen, Hot3000 and Energy Star (NRC 2009b, Energy Star 2010a, Energy Star 2010b, NRC 2010a). ECMs for solar array analysis and whole building heating analysis that may require large computing power will have the ability to be run using cloud computing on off site servers although basic solar applications have already been developed for the iPhone (NJSolar 2010, SolarTools 2009). A program like HOT3000 can be used to breakdown energy use within the home, project retrofit savings, evaluate specific architectural elements and simulate heating and cooling conditions (NRC 2009b). In addition a program like RETScreen could provide the ability to assess the application of renewable installations like solar arrays and small-scale wind power (NRC 2010a). It should be pointed out that because smartphones have a limited screen size professional applications such as energy service companies auditing university campuses (Pearce and Miller, 2006) slightly larger devices like tablets, which are based on smart phone technology, would be more suitable. However, the more ubiquitous smartphone technology is more appropriate for the greatest range of users.

\subsection{Error Analysis}

The ability of a home user to make calculations with the aid of technology on the same level of a trained professional is a major assumption made within this paper. This ability will be addressed directly in the quality of instructions that the user will follow when completing the audit using instructional videos and “help' functionality. Of critical importance is the ability to measure distances and input data into the program. This distance measurement, which is the most time-consuming data gathering step for professional auditors (normally accomplished with a tape measurer, low cost laser distance finder, or estimations for hard to reach areas) can be greatly sped up with the use of the camera embedded in smartphones and a reference object. The method uses an algorithm and lens optical information to determine the length of objects by detecting the object contours and measuring pixel length by comparing distances to the reference object (Suhadolnik et al. 2009). 


\subsection{Constant User Engagement and Geo-Spatial Awareness}

Unlike the one time nature of traditional energy audits the smartphone audit will be able to run periodic simulations that account for changing conditions and alert the user when specific conditions are met. Information is not limited to static content as there are several variables (e.g. utility rates, new products, regulations, incentives, prices, etc.), which constantly change that would affect the economic results for ECMs targeted by a smartphone audit. In addition to the federal rebates that are currently included in traditional energy audits, provincial, civic, utility specific as well as commercial offers can be included in the smartphone application and kept up to date. Furthermore, as factors change smartphones have the ability to push alerts to users when ECMs rise above a given internal rate of return or savings threshold. This has the potential to help keep users actively involved and constantly engaged with the energy efficiency of their homes.

All of the features of the energy audit will be enhanced by the location-aware capabilities of the smartphone including GPS mapping (e.g. utility rates and incentives are used in the calculation based upon the audit location automatically). This type of geo-spatial awareness could assist small startup companies or tailored government rebate programs. For example, in an area when many houses need basement insulation (as determined by the completion of smartphone audits uploaded and mapped on the server) a company could offer a discount that drops the install price below a likely user-set threshold (e.g. $10 \%$ internal rate of return) and encourages users to make the retrofit. Alternatively, with two way flows of information protected for user privacy, the government could subsidize, for example, batting insulation in a given area to encourage retrofits and push it above a similar threshold. Finally, positive peer-pressure may be encouraged by offering tax rebates or lucrative coupons to streets or blocks that have $100 \%$ audit completion with maps showing audit status of homes and facilitated through built in social networking types features.

\subsection{ECM Ranking by IRR and User Education}

Being that all of the ECMs can be characterized by internal rate of return (IRR) and investment costs, they can be independently ranked and categorized for comparison. This will allow users to complete the most effective retrofits that meet their investment goals and capital abilities. The economic modeling, which generates these IRRs needs to be open and based on rigorous data, as it is economic data that is key to communicating to users about efficiency decisions and an integral part of the necessary education process (Pearce and Russill 2005). For example, a study performed by Magat, Payne and Brucato (1986) showed that when ECMs were presented to the homeowner in a list ranked by payback period they were able to achieve, on average, twice the energy savings per dollar as compared to the way information is typically presented after an energy audit. More recent work has argued for IRRs in place of simple paybacks and has shown that educating the user about the financial rate of return and the potential carbon dioxide $\left(\mathrm{CO}_{2}\right)$ savings can encourage environmentally and energetically rational decisions (Pearce et al. 2009). With the additional features now available in smartphones, video tutorials and graphical representation of savings are also available to assist in the educational process. An example of the type of video references available is Massachusetts Institute of Technology (MIT) Open Course Ware project (2010).

\subsection{Continuous Evolution}

Internet connectivity allows the potential smartphone energy audit application to be updated and added onto through its life. This will lead to an ever-improving user experience and allow users or 
P. Leslie, J. M. Pearce, R. Harrap, S. Daniel, “The application of smartphone technology to economic and environmental analysis of building energy conservation strategies”, International Journal of Sustainable Energy 31(5), pp. 295-311 (2012).

DOI: http://dx.doi.org/10.1080/1478646X.2011.578746

corporations to create their own ECMs and incorporate them into the software. This functionality will provide a challenge due to the need for future proofing and ensuring platform independence. However, these challenges can be overcome using an open source methodology similar to how companies are open sourcing their platforms to gain and maintain functionality (Apple 2010, Google 2010).

\subsection{Example ECM}

One example of an ECM for the smartphone application would be one for lighting lamp retrofits. A screen view of what an ECM App could look like on an iPhone, is shown in Figure 1.

As can be seen in Fig. 1, the user would choose their house, energy sources and payment, and then can drill down into specific ECMs such as lighting retrofits, which are shown. The annual energy savings from the replacement of a light bulb is given by the difference in the power consumption of the two bulbs multiplied by the number of hours used per year. Economic analysis also requires the cost and rate structure of electricity, costs of the various types of bulbs and lifetime of bulb. These inputs would come from a query of available internet databases. An economic analysis with these inputs produces monetary savings per year, energy savings per year, $\mathrm{CO}_{2}$ savings per year, and internal rate of return (IRR). This analysis can be done for replacements or new projects to inform the users in order to help them make better decisions. Simplified versions of several ECMs including one for lighting are available from Energy Star (Energy Star 2010a) and a number of open source ECMs on green IT and other appropriate technologies are available on Appropedia (Appropedia 2010). The use of a smartphone allows for many additions to these ECM's. The fast internet connection will also allow for real time product pricing information, electricity prices, available rebates and create a more holistic economic modeling tool.

\section{Methodology}

To assess the potential benefits of using smartphones for home energy audits, a comparison of the resources that it would take to complete energy audits on all the homes in a given area is compared to those from a standard energy audit. The resources that were quantified include driving time and auditing time required for the two different types of audits in a region. The region chosen for the case study considered is that of Hearthmakers Energy Cooperative Inc., based in Kingston, ON. Hearthmakers is a member of Green Communities Canada who is licensed by Natural Resources Canada to provide standardized home energy audits. The audits are meant to assist homeowners in making retrofit decisions to improve comfort and the energy efficiency of their homes. The area assigned to Hearthmakers was compared to a Statistics Canada census map for subdivisions (Statistics Canada 2009). The geographic census areas used in this paper for dwelling counts were confirmed by Cooper (2010a) on behalf of Hearthmakers and are shown in Figure 2.

Using census data (Statistics Canada 2009), the number of dwellings was found for each of the 17 sub-divisions. To find the average driving time and distance to each dwelling within a subdivision, Google's Maps online software was used (Google 2010c). The average driving time inside Kingston was estimated using the location of Hearthmakers and assuming average dwelling density inside city limits. The total driving distance, $D_{D}$, and times, $D_{\text {TT }}$, to the center of each county were calculated from Hearthmakers home office in Kingston and totaled using: 


$$
\begin{aligned}
& \left.D_{D}=\sum_{n=1}^{17} 2 N_{D w} D_{S}\right) \\
& \left.D_{T T}=\sum_{n=1}^{17} 2 N_{D w} D_{t}\right)
\end{aligned}
$$

where $N_{D w}$ is number of dwellings in each subdivision, and $D_{s}$ and $D_{t}$ are average driving distance [km] and time [hrs], respectively to each dwelling for the individual subdivisions. Total fuel consumption, $\mathrm{F}_{\mathrm{c}}$ [L], was then found using the results of Equation (1) by:

$$
\mathrm{F}_{\mathrm{C}}=\mathrm{D}_{\mathrm{D}} \mathrm{C}_{\text {Average }}
$$

where $\mathrm{C}_{\text {Average }}$ is national average fuel consumption [L/100km], which for gasoline powered vehicles in Canada is $9.14 \mathrm{~L} / 100 \mathrm{~km}$ (NRC 2009d). Then the total emissions $\mathrm{E}_{\mathrm{T}}[\mathrm{kg}]$ can be calculated using the results of Equation (3) by:

$$
\mathrm{E}_{\mathrm{T}}=\mathrm{F}_{\mathrm{c}} \mathrm{G}
$$

where $\mathrm{G}$ is the $\mathrm{CO}_{2}$ emitted by burning $1 \mathrm{~L}$ of fuel in perfect combustion and is set as $2.34 \mathrm{~kg} \mathrm{CO}_{2} / \mathrm{L}$ of gasoline (U.S. Department of Energy). Using the energy content of gasoline, and the result of Equation 3 , the energy consumed $\left(Q_{D}\right)$ while driving can be found:

$$
\mathrm{Q}_{\mathrm{D}}=\mathrm{F}_{\mathrm{C}} \mathrm{H}
$$

where $\mathrm{H}[\mathrm{MJ} / \mathrm{L}]$ is the average energy content of a liter of gasoline of $31.7 \mathrm{MJ} / \mathrm{L}\left(\mathrm{O}^{\prime}\right.$ Hayre et al. 2009, Ristinen and Kraushaar 1999). Average yearly energy savings $Q_{s}[\mathrm{MJ}]$ due to an audit can be calculated using the average effectiveness of an audit.

$$
\mathrm{Q}_{\mathrm{s}}=\mathrm{N}_{\mathrm{Dw}} \eta \mathrm{Q}_{\mathrm{Av}} \mathrm{P}_{\text {heat }}
$$

where $\eta$ is average energy savings reduction fraction (i.e. 0.30 for $30 \%$ energy reduction) from conducting an audit, $\mathrm{Q}_{\mathrm{Av}}$ is the average residential energy consumption $[\mathrm{MJ}]$ and $\mathrm{P}_{\text {heat }}$ is the average fractional amount of energy in a residential house that is used for heating. Natural Resources Canada (NRC) estimates average heating savings of 30\% due to an energy audit when recommended actions are performed (NRC 2010b). Average energy intensity for a single Canadian home is 111.45 GJ/yr (30,958 $\mathrm{kWh} / \mathrm{yr}$ ) of which $62.7 \%$ is use for space heating (NRC 2009a).

The energy and emissions savings ability of the two audit programs are compared using a sensitivity analysis with four cases. Two cases were used to represent the emissions reduction capabilities of traditional home energy audits (TA) in the case area:

1. TA Case 1: The base traditional audit case will be that of Hearthmakers current performance. This includes 900 audits per year, as confirmed by Cooper (2010b).

2. TA Case 2: The optimistic traditional audit case accounts for the maximum amount of audits that Hearthmakers could complete in one year. It assumes the all six auditors would work full time 40 hours a week, 52 weeks per year. Accounting for an average of 77 minutes round trip driving time to each dwelling and 3 hours required to perform an audit, gives 2914 audits per year.

Two cases were used to represent the emission reduction capabilities of a smartphone based auditing system. Since the uptake rate of the smartphone-based auditing software is unknown, an estimate is made using a curve representing the diffusion of similar innovations following the models 
P. Leslie, J. M. Pearce, R. Harrap, S. Daniel, “The application of smartphone technology to economic and environmental analysis of building energy conservation strategies”, International Journal of Sustainable Energy 31(5), pp. 295-311 (2012).

DOI: http://dx.doi.org/10.1080/1478646X.2011.578746

outlined by Rogers (1983). In 2008 74.3\% of Canadian homes had mobile phone subscriptions (CRTC 2009). Smartphones represented approximately $20 \%$ of the mobile phone sales market in North America at the end of 2008, a 69\% growth in sales for the year (Gartner, 2009). This provides an innovation diffusion curve starting value of 23,330 dwellings that own smartphones in the case area, which is bounded by 116,651 smartphone owning homes out of the 157,000 at full penetration (Statistics Canada 2008). It should be noted that these values are on the conservative side of smartphone penetration due to the lack of accounting for increasing mobile phone adoption and increasing population. The adoption and use of the software is also modeled using a diffusion curve, with the base case being zero users in the first year. The two specific smartphone (SM) cases are:

1. $\quad$ SM Case 1: The conservative smartphone case is modeled using the diffusion curve parameters of the DOE-2 modeling software adoption where the innovation co-efficient (p) is 0.0005 and imitation co-efficient (q) in 0.656 (U.S. Department of Energy, 2004). In this case both the software adoption and smartphone penetration are modeled using these co-efficients of diffusion.

2. $\quad$ SM Case 2: The slightly more optimistic case is modeled using the diffusion curve parameters of the Low-e window adoption where $\mathrm{p}$ is 0.0577 and $\mathrm{q}$ is 0.2729 (U.S. Department of Energy, 2004). In this case both the software adoption and smartphone penetration are modeled using these co-efficients of diffusion.

For all cases, the energy savings are assumed to be realized the year following implementation. The cumulative energy and emissions savings of the two programs rely heavily on the effectiveness of the audit to account for energy savings. Energy savings are restricted to improvements in heating efficiency for both cases despite a large potential for reductions in electricity use by ECMs within the smartphone application. A sensitivity analysis was performed on the variable effectiveness of each of the audit scenarios in order to generalize the results of this study.

\section{Results}

Within the case study area in southern Ontario, there are 157,000 dwellings (Statistics Canada 2008). To complete audits using the traditional audit process an auditor has to drive to each separate dwelling. Using Equations 1 and 2 the audit process is found to require 16,000,000 km and 202,000 hours of driving. Equations 3 and 4 show that this travel would result in 1,460,000 $\mathrm{L}$ of gasoline being consumed producing 3,420 tons of $\mathrm{CO}_{2}$ emissions. Although the energy and emissions due to travel are significant, it should be noted that they represent less than $1 \%$ of energy reductions at even the lowest audit effectiveness. To complete the audits themselves would require 472,000 hours resulting in a total completion time with driving of 674,000 hours of work. Based on 52 weeks a year, 40 hours a week, the 6 auditors that Hearthmakers currently employs will require a remarkable 55 years to complete the energy audits for all the dwellings in the region.

The results of diffusion of the auditing scenarios in the case area are shown in Figure 3. As can be seen in Figure 3, both traditional auditing scenarios assume linear growth of audits performed based on the limits of Hearthmakers and their area, while the smartphone based audits are based on a diffusion innovation curve that models how new innovations are adopted by consumers. Although the traditional audits provide further coverage in the first few years, the smartphone based audits rapidly overtake traditional audits and by 20 years have more than a factor of 5 or a factor of 2 additional audits completed depending on the choice of assumptions. It is very important to note that the upper bound of the smartphone audits curve is based on the current amount of mobile phones being used in the area as well as the population. These two boundaries are subject to change in the future as mobile phones 
become the norm and population growth occurs. In particular the uptake rate of smartphones is accelerating and should be viewed as a very conservative estimate.

The cumulative $\mathrm{CO}_{2}$ savings for the Hearthmakers territory and the four auditing case types assuming an audit effectiveness of $30 \%$ are shown in Figure 4 . As can be seen in Figure 4, the cumulative $\mathrm{CO}_{2}$ savings from smartphones and will out-pace traditional audits in year 13 and year 17 for the optimistic and conservative cases respectively and continue decades.

Finally, the results of the sensitivity analysis on effectiveness of each of the audit scenarios is summarized in Table 2, in order to generalize the results of this study. Table 2 shows the impact of the four cases in $\mathrm{Mt}$ of $\mathrm{CO}_{2}$ saved, and are based on the length of time and the audit effectiveness. Table 2 shows that for each combination of length and audit effectiveness that the highest cumulative savings occurs using the optimistic smartphone case.

\section{Discussion}

The results of the case study show that the smartphone based energy auditing system has a high potential for accelerated energy and emissions savings, when compared to the traditional energy auditing process that currently exists. Firstly, the yearly savings due to reduction of driving time alone show potential for energy consumption reduction of 12,800 MWh and emissions reduction of 3420 tonnes, although they are dwarfed by the energy and emission reductions accrued from ECM deployment in the same number of homes. The primary benefit of the smartphone based energy auditing system is the parallel auditing of thousands of homes in a very short time. Although, both the government and the home owner will end up incurring costs for the 647,000 hrs of work time required to audit all the households in the area, the smartphone based approach allows these hours to be accomplished by many homeowners simultaneously, whereas this is unfeasible for the traditional approach due to the lack of qualified personnel. With the current capabilities and workforce deployed by Hearthmakers, the case study area will take 55 years to audit every residence. This is an unacceptable amount of time with respect to global greenhouse gas emissions targets according to current research (IPCC 2007, Richardson et al. 2009). Another advantage of homeowner audit is they can keep on auditing their home and adjust the home changes according to their previous ECM. With the current professional audit, this is not possible without considerable expense.

The potential reduction of 49,000 tones of $\mathrm{CO}_{2}$ per year, for the case study dwellings, based on an effectiveness of $\eta=0.30$ is significant. If developed properly, and applied on a larger scale, implementation of this type of energy efficiency program could play an integral role in Canada's future environmental strategy. The potential of the smartphone application to be applied on a large scale after a short development time is one of major advantages of the program. Figure 3 and 4 showed that although the traditional audits provide further coverage in the first few years the smartphone based audits rapidly overtake traditional audits and provides substantially more energy and emission savings over the medium term.

Innovation diffusion analysis, including a one year development time for the smartphone software coding, shows that total audits completed by the smartphone case will exceed optimistic traditional audits case at year 12. In year two the higher diffusion analysis shows only 321 audits completed. A government subsidy or promotional program that increases this initial up take could dramatically 
P. Leslie, J. M. Pearce, R. Harrap, S. Daniel, “The application of smartphone technology to economic and environmental analysis of building energy conservation strategies”, International Journal of Sustainable Energy 31(5), pp. 295-311 (2012).

DOI: http://dx.doi.org/10.1080/1478646X.2011.578746

improve these very conservative projections. The sensitivity analysis shown in Table 2 shows the energy savings potential of both programs for a variety of audit effectiveness values. It can be seen that for the same year and effectiveness the smartphone audit in the less conservative case has a higher reduction capability in every instance at high deployment rates.

The primary deficiency of the smartphone audit as compared to the traditional audit is the lack of a blower door test that is used to measure how well the house is sealed and provides a quantitative feedback when pre and post retrofit audits are compared. Lacking the ability to complete this part of the audit the smartphone will need to be coupled with information and instructions, possibly in video format, for the home user to find cracks and seal off likely sources of air infiltration. An example of this procedure is already outlined by Energy Star (Office of Air and Radiation 2000). Currently in Canada subsidies for energy efficient retrofits are awarded based on a before and after government regulated inspections (ecoEnergy 2009). The move to a user performed smartphone based audit would require a different subsidy program. A new tailored program would either use an across the board subsidy or individual purchasing allowance system for energy efficient products and materials.

A considerable advantage of a smartphone based energy audit program is its ability to engage users. The program has greater impact then a one time audit because of the continual feedback and constant updating. A study by McClelland and Cook showed that households that received continuous feed-back during the study about the monetary cost of electricity reduced their energy consumption by $12 \%$ compared to a control group (McClelland and Cook 1979-1980). A study by Winett and Kagel showed that the way in which energy efficiency information is presented to the public can yield energy use reductions as great or greater than relatively large increases in the price of energy (Winett and Kagel 1984). The innovative user interface of many new smartphones provides an ideal way to present energy efficiency information to engage the user in the most effective way. The recent explosion in growth of social networks and online peer groups and the success of crowdsourcing provides some examples of the additional utility of using a smartphone platform for energy audits.

The estimated uptake rates of the smartphone model used in this paper are very likely conservative as there is clear evidence that a strong case for faster uptakes, especially among younger people (who make up the majority of smartphone users), via a link to social networking. Facebook, 4square, Flicker, etc. are all social phenomena and this application is more likely to follow a more rapid technological diffusion path than the DOE or high-performance window models chosen within this paper.

\subsection{Improving ECM Adoption Rates}

Adoption of many energy efficient and economically beneficial technologies has been slow in the residential market. One such technology that has been analyzed is the movement to CFL bulbs from incandescent bulbs. A low adoption rate occurs despite a common payback rate of less than one year (Bertoldi and Atanasiu 2006), which is an IRR of over 100\% (Pearce et al. 2009). A major deterrent to energy efficient equipment adoption tends to be the relatively high capital costs and the consumers inability to estimate the operating costs (Maria et al. 2010). In the case of the smartphone energy audit that operating cost estimation would be done for the consumer using simple and easily understood inputs as shown in Figure 1. The main advantage, however, will simply be education of ECM products' existence. A study performed in Ireland on CFL bulb adoption showed that $50 \%$ of the respondents pointed at the lack of awareness of the benefits and the lack of awareness of even the existence of such measures as a reason for not using CFLs (Maria et al. 2010). The study also showed that education was 
more positively correlated to CFL adoption then respondents' views on environmental protection. This is supported by comparing a government CFL campaign in Germany (Prose \& Wortmann 1991) to a personalized educational approach (Pearce and Russill 2005). In 1990-1991 in the state of SchleswigHolstein in Germany a government campaign, which concentrated on households, was run through mass mailed leaflets, newspaper articles, and a balloon release, resulted in an estimated 20,000 CFLs being purchased. During the campaign $8.7 \%$ of Kiel households installed CFLs for the first time and an additional $6.8 \%$ of households which already had CFLs purchased more. Thus, a total of $15.5 \%$ of a possible $48.7 \%$ that were cognizant of exposure to the campaign for a total success rate of $31.8 \%$. In contrast a method focused on education was more effective having an success rate of $67 \%$ (Pearce and Russill 2005) attributed to (a) the motives for adoption could be tailored for the individual, (b) economic results were personalized, and (c) interpersonal contact helped to more fully explain the concept. The smartphone energy audit shares the first of two strengths.

If the findings are assumed to apply to all types of consumer based energy efficient technology, several conclusions can be made: i) educating the user about economic outlook and analysis is integral to the success of the smartphone energy audit, and ii) education of a population about the possibilities and benefits that exist in energy efficient technology are necessary for wide spread efficient technology adoption. These two factors that dictate the success of technology adoption are also the defining features of the smartphone software.

\section{Conclusions}

It is well established that building energy audits provide occupants and owners with valuable information and tools to help reduce emissions, conserve energy and reduce operating costs. This paper investigated the potential effects of advances in smartphone technology as a tool to implement building energy audit programs to increase energy conservation measure (ECM) uptake and increase the resulting environmental and economic benefits. It is clear that a versatile, easy to use program designed to run on smartphones, which could be widely distributed, could end up increasing the effectiveness of government-sponsored energy efficiency programs and provide the ability to instantly respond to changing conditions within the home retrofitting market. Fast Internet connections and the technical evolution of modern smartphones provide a energy audit platform with additional features including: i) quasi-real time analysis, ii) dynamic information sharing and continuous user engagement, iii) geospatial customization, iv) an enhanced catalog of ECMs, v) ECM ranking and user education, and vi) the ability to constantly evolve. A case study for Southeastern Ontario of 157 thousand homes is provided that shows that 55 years is needed to complete the energy audits for all the dwellings in the region following a traditional model. However, the results of the smartphone based audit program rapidly overtakes traditional audits and by 20 years have more than a factor of 2 to 5 additional audits completed, with the cumulative carbon dioxide savings from smartphones surpassing traditional audits between 13 and 17 years with conservative assumptions. This paper shows that an advanced and expanded home energy auditing program that uses smartphone technology could provide significant economic and environmental benefits as compared to current programs and have a significant contribution to largescale $\mathrm{CO}_{2}$ reduction strategies. 
P. Leslie, J. M. Pearce, R. Harrap, S. Daniel, “The application of smartphone technology to economic and environmental analysis of building energy conservation strategies”, International Journal of Sustainable Energy 31(5), pp. 295-311 (2012).

DOI: http://dx.doi.org/10.1080/1478646X.2011.578746

\section{Acknowledgements}

The authors would like to acknowledge Hearthmakers Energy Cooperative Inc. for their cooperation in the study and technical assistance from H. Nguyen. This work was supported by GEOIDE/NCE.

\section{References}

Amazon, 2010. Amazon App for iPhone and iPod Touch [online]. Available from: http://www.amazon.com/gp/feature.html?ie=UTF8\&docId=1000291661 [Accessed 20 April 2010]

Apple, 2010. iPhone Dev Center [online] Available from: http://developer.apple.com/iphone/index.action [Accessed 27 June 2010]

Appropedia, 2010. Green IT [online]. Available from: http://www.appropedia.org/Category:Green IT [Accessed 12 May 2010]

Azuma, R. T. A Survey of Augmented Reality. In Presence: Teleoperators and Virtual Environments, 1997: 355-385.

Bertoldi, P., \& Atanasiu, B., 2006. Residential Lighting Consumption and Saving Potential in the Enlarged Eu. EDAl '06 Conference, 21-23 June 2006 London, UK: European Commission - DG Joint Research Centre, Institute for Environment and Sustainability.

Broll W., Lindt I., Herbst I., Ohlenburg J., Braun A.-K., Wetzel R. 2008. Towards next-gen mobile AR games. IEEE Computer Graphics and Applications, vol. 28, n²4, pp.40-48.

Corbett, J., Webster, J. Sayili, K., Zelenika-Zovko, I. and Pearce, J. 2010. Developing and Justifying Energy Conservation Measures: Green IT under Construction. Proceedings of the Sixteenth Americas Conference on Information Systems, Lima, Peru, August 12-15, 2010. pp 1-8.

Cooper, L. (csr@hearthmakers.org), 25 Mar 2010a. RE: Hearthmakers area. Email to P. Leslie (patrickaleslie@gmail.com)

Cooper, L. (csr@hearthmakers.org), 16 Feb 2010b. EcoEnergy Audit. Email to P. Leslie (patrickaleslie@gmail.com)

CRTC, 2009. Communications Monitoring Report. Ottawa: Canadian Radio-Television and Telecommunications Commission

DiBona, C., Ockman, S. and Stone, M. (Eds). 1999. Open Sources. Sebastopol, CA: O'Reilly \& Associates.

ecoEnergy, 2009. Grant Table for ecoEnergy retrofit - Homes. Ottawa: Natural Resources Canada Energy Star, 2010a. Energy Saving Calculators from ENERGY STAR [online]. U.S. Small Business Administration. Available from: http://www.business.gov/manage/green-business/energyefficiency/calculate-savings/energy-saving-calculator.html [Accesed 04 April 2010]

Energy Star, 2010b. Energy Star Qualified Products [online]. U.S. Small Business Administration. Available from: http://www.energystar.gov/index.cfm?fuseaction=find a product [Accesed 04 April 2010]

EnergyCAP, 2010. EnergyCAP home page [online]. Available from: http://www.energycap.com/ [Accessed 08 April 2010]

ESP-r, (n.d.). ESP-r home page [online] Engineering Department, University of Strathclyde. Available from: http://www.esru.strath.ac.uk/Programs/ESP-r.htm [Accessed 20 April 2010] 
Gartner, 2009. Gartner Says Worldwide Smartphone Sales Reached Its Lowest Growth Rate With 3.7 Per Cent Increase in Fourth Quarter of 2008 [online] Available from: http://www.gartner.com/it/page.jsp?id=910112 [Accessed 14 January 2010]

Google, 2010a. Google Goggles [online] Google Mobile Labs. Available from: http://www.google.com/mobile/goggles/\#landmark [Accessed 20 April 2010]

Google, 2010b. Andriod Open Source Project [online] Available from: http://source.android.com/index.html [Accessed 27 June 2010]

Google, 2010c. Google Maps [online]. Available from: http://maps.google.com [Accessed 20 April 2010]

Government of Alberta, 2009. Home Energy Evaluation Available Rebates. Climate Change Central, Edmonton: Government of Alberta.

Kemans, B., (a.d.) RulerPhone [online]. Available from: http://benkamens.com/rulerphone/sale.html [Accessed 27 Jun 2010])

Lee, S.-Y.T., Kim, H.-W., Gupta S., 2009. Measuring open source software success, Omega, 37, 426438

Pitt, L. F., Parent, M., Junglas, I., Chan, A., Spyropoulou, S., (in press). Integrating the smartphone into a sound environmental information systems strategy: Principles, practices and a research agenda, The Journal of Strategic Information Systems, Available online 25 October 2010, DOI: 10.1016/j.jsis.2010.09.005.

Magat, W. A., Payne, J. W., \& Brucato, P. F., 1986. How important is information format? An Experimental Study of Home Energy Audit Programs. Journal of Policy Analyis and Management, 6 (1), 20-34

Maria, C., Ferreira, S., \& Lazarova, E., 2010)]. Shedding light on the light bulb puzzle: The role of attitudes and perceptions in the adoption of energy efficent light bulbs. Scottish Journal of Political Economy, 57 (2)

McClelland, L., \& Cook, S. W., 1979-1980. Energy conservation effects of continuous in-home feedback in all-electric homes. Journal of Environmental Systems , 9, 169-173.

MF Software, 2009. CFL Calculator [online]. Available from: http://mfsoftwareonline.com/page4/page4.html [Accessed 4 April 2010]

MIT, 2010. MIT Open Course Ware [online] Available from: http://ocw.mit.edu/courses/audio-videocourses/ [Accessed 27 June 2010]

NJSolar, 2009. Solar PV [online]. Available from: http://www.njsolarconsulting.com/solar pv.htm [Accessed 16 June 16, 2010]

NRC Climate Change Impacts and Adaptations Division, 2007a. From Impacts to Adaptation: Canada in a Changing Climate 2007. Ottawa: Natural Resources Canada.

NRC, 2007. 2007b. Survey of Household Energy Use (SHEU-2007) - Data Tables [online]. Office of Energy Efficiency. Available from: http://oee.nrcan.gc.ca/corporate/statistics/neud/dpa/data e/sheu07/tables.cfm?attr=0 [Accessed 29 March 2010]

NRC, 2009a. Residential Sector - Energy Use Analysis Homes [online]. Office of Energy Efficiency. Available from: http://oee.nrcan.gc.ca/corporate/statistics/neud/dpa/tablesanalysis2/res 001 e 1 4.cfm?attr=0 [Accessed 20 April 2010]

NRC, 2009b. Software Tools: HOT3000 [online]. Office of Energy Efficiency. Available from: http://canmetenergy-canmetenergie.nrcan-rncan.gc.ca/eng/software tools/hot3000.html [Accessed 20 April 2010] 
P. Leslie, J. M. Pearce, R. Harrap, S. Daniel, “The application of smartphone technology to economic and environmental analysis of building energy conservation strategies”, International Journal of Sustainable Energy 31(5), pp. 295-311 (2012).

DOI: http://dx.doi.org/10.1080/1478646X.2011.578746

NRC, 2009c. Directory of Energy Efficiency and Alternative Energy Programs in Canada [online]. Office of Energy Efficiency. Available from: http://oee.rncan.gc.ca/corporate/statistics/neud/dpa/policy e/programs.cfm?attr=0 [Accessed 20 April 2010]

NRC, 2009d. Transportation Sector Canada, Table 47: Explanatory Variables [online]. Office of Energy Efficiency. Available from: http://www.oee.nrcan.gc.ca/corporate/statistics/neud/dpa/tablestrends2/tran ca 47 e 4.cfm?attr=0 [Accessed 20 April 2010]

NRC, 2010a. RETScreen International [online]. Office of Energy Efficiency. Available from: http://www.retscreen.net/ang/home.php [Accessed 20 April 2010]

NRC, 2010b. ecoEnergy Retrofit - Homes [online]. Office of Energy Efficiency. Available from: http://oee.nrcan.gc.ca/residential/personal/retrofit-homes/questions-answers.cfm?attr=4\#intro2 [Accessed 20 April 2010]

Occipital, 2010. RedLaser [online] Available from: http://redlaser.com/ [Accessed 20 April 2010]

Office of Technology Assessment, 1979. Residential Energy Conservation. Washington: Congress of the United States

O'Hayre, R., Cha, S., Colella, W., \& Prinz, F. B., 2009. Fuel Cell Fundamentals. Hoboken, NJ: John Wiley \& Sons.

Ontario Home Energy, 2010. It pays to be green. Ontario: Ontario Ministry of Energy and Infrastructure.

Osborn, J., Goldman, C., Hopper, N., \& Singer, T. 2002. Assessing U.S. ESCO industry performance and market trends: Results from the NAESCO database project. Lawrence Berkeley National Laboratory: Lawrence Berkeley National Laboratory. LBNL Paper LBNL-50304.

Parry M.L., O.F. Canziani, J.P. Palutikof, P.J. van der Linden and C.E. Hanson, Eds., 2007, Climate Change 2007: Impacts, Adaptation and Vulnerability. Contribution of Working Group II to the Fourth Assessment Report of the Intergovernmental Panel on Climate Change, Cambridge University Press, Cambridge, UK, 982pp.

Pearce, J.M. And Miller, L.L. 2006. Energy Service Companies as a Component of a Comprehensive University Sustainability Strategy, International Journal of Sustainability in Higher Education, 7(1), 16-33.

Pearce, J. M. and Russill, C., 2005. Interdisciplinary Environmental Education: Communicating and Applying Energy Efficiency for Sustainability. Applied Environmental Education and Communication, 4 (1), 65-72.

Pearce, J. M., Denkenberger, D., and Zielonka, H., 2009, Accelerating Applied Sustainability by Utilizing Return on Investment for Energy Conservation Measures. International Journal of Energy, Environment and Economics, 17 (1), 61-80.

Pettey, C., \& Tudor, B., 2010. Gartner Says Worldwide Mobile Phone Sales to End Users Grew 8 Per Cent in Fourth Quarter 2009; Market Remained Flat in 2009. Gartner. Available from: http://www.gartner.com/it/page.jsp?id=1306513 [Accessed 20 April 2010]

Richardson, K., et al., 2009. Synthesis report. Climate Change: Global Risks, Challenges \& Decisions. Copenhagen climate change congress, 10-12 March 2009 Copenhagen, Denmark: University of Copenhagen

Ristinen, R. A., \& Kraushaar, J. J., 1999. Energy and the Environment. Hoboken, NJ: John Wiley \& Sons.

Rogers, Everett M. 1983. Diffusion of Innovations. $5^{\text {th }}$ Ed. New York: Free Press 
SolarTools 2010, SolarTools for the iPhone [online]. Available from http://www.solartoolsapp.com/ [Accessed 16 June 16, 2010]

Solmetric Inc., 2010. Solmetric PV Designer [online]. Available from: http://www.solmetric.com/pvdesigner.html [Accessed 20 April 2010]

Statistics Canada, 2009. Census Subdivision, Ontario - South [online]. Available from: http://geodepot.statcan.gc.ca/2006/13011619/1907032006 05-eng.jsp?province=CDCSD\&Go=Next\&fileName=\#geo [Accessed 20 April 2010]

Statistics Canada, 2008. Census subdivisions (CSDs) [online]. Available from: http://www12.statcan.gc.ca/english/census06/data/popdwell/SubTables.cfm?T=300 [Accessed 20 April 2010]

Stern, N., 2007. The Economics of Climate Change. Cambridge, UK: Cambridge University Press. Stevens, H., \& Pettey, C., 2009. Gartner Says Worldwide Smartphone Sales Reached Its Lowest Growth Rate With 3.7 Per Cent Increase in Fourth Quarter of 2008. Gartner. Available from: http://www.gartner.com/it/page.jsp?id=910112 [Accessed 20 April 2010]

Suhadolnik, A., Petrisic, J., \& Kosel, F., 2009. An anchored discrete convolution algorithm for measuring length in digital images. Journal of the International Measurement Confederation, 42 (7), 1112-1117

Thomas V., Daniel S., Pouliot J. 2010. 3D modeling for mobile augmented reality in unprepared environment. In Advances in 3D Geo-Information Sciences, Lecture Notes in Geoinformation and Cartography Series, Ed. T. H. Kolbe, G. König and N. Claus, 3D GeoInfo Conference, Berlin, Germany, November 3-4, Springer, 2010.

U.S. Department of Energy, (n.d.). Voluntary Reporting of Greenhouse Gases Program [online]. Energy Information Administratrion. Available form: http://www.eia.doe.gov/oiaf/1605/coefficients.html [Accessed 13 of June 2010]

U.S. Department of Energy, 2004. Methodological Framework for Analysis of Buildings-Related Programs: The GPRA Metrics Effort. Richland, Washington: Pacific Northwest National Laboratory

Office of Air and Radiation, 2000. Air Sealing: Building Envelope Improvement. Washington: Environmental Protection Agency.

U.S. EPA, U.S. DOE, 2009. Home Performance with Energy Star. Washingston: Environmental Protection Agency and Department of Energy.

Watson, R.T.,Pitt, L.F., Berthon, P., and Zinkhan, G.M. 2002. U-Commerce: Expanding the Universe of Marketing Journal of the Academy of Marketing Science 30, 333-347.

Winett, R. A., Kagel, J. H., 1984. Effects of Information Presentation Format on Resource Use in Field Setting. Journal of Consumer Research 11 (2), 655-667 
P. Leslie, J. M. Pearce, R. Harrap, S. Daniel, “The application of smartphone technology to economic and environmental analysis of building energy conservation strategies”, International Journal of Sustainable Energy 31(5), pp. 295-311 (2012).

DOI: http://dx.doi.org/10.1080/1478646X.2011.578746

\section{Table Captions}

\begin{tabular}{|c|c|c|c|c|}
\hline Feature & 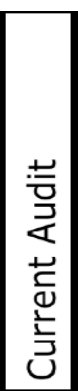 & 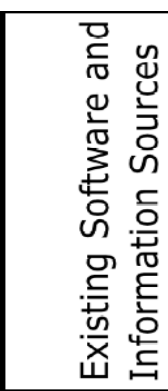 & 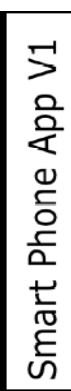 & 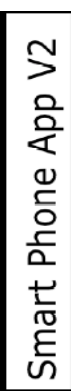 \\
\hline Air leakage calculation & $x$ & & & \\
\hline Certified completion of retrofit & $x$ & & & \\
\hline $\begin{array}{l}\text { Rankings against comparable national } \\
\text { or regional homes }\end{array}$ & $x$ & $x^{1}$ & $x$ & $x$ \\
\hline Energy consumption breakdown & $x$ & $\overline{x^{2}}$ & $x$ & $\mathrm{x}$ \\
\hline Rebate suggestions: Federal & $x$ & $x^{3}$ & $x$ & $x$ \\
\hline $\begin{array}{l}\text { Envelope heating analysis with post } \\
\text { retrofit energy savings projection }\end{array}$ & $x$ & $x^{2}$ & $x$ & $x$ \\
\hline $\begin{array}{l}\text { Rebate sugestions: Provincial, Civic, } \\
\text { Commercial }\end{array}$ & & $x^{4}$ & $x$ & $x$ \\
\hline $\begin{array}{l}\text { Thermostat replacement analysis with } \\
\text { real time savings estimator }\end{array}$ & & $x^{2}$ & $x$ & $x$ \\
\hline $\begin{array}{l}\text { Continual project tracking, plus bill } \\
\text { tracking }\end{array}$ & & $x^{5}$ & $x$ & $x$ \\
\hline $\begin{array}{l}\text { Real time advanced economics } \\
\text { including energy price projections, } \\
\text { CO2 projections, IRR, and graphical } \\
\text { representation }\end{array}$ & & & $x$ & $x$ \\
\hline ECM suggestions and rankings & & & $x$ & $x$ \\
\hline $\begin{array}{l}\text { Appliance analysis using online } \\
\text { databases }\end{array}$ & & $x^{6,7,8}$ & $x$ & $x$ \\
\hline Product recognition using camera & & $x^{9,10,11}$ & & $x$ \\
\hline $\begin{array}{l}\text { Geo-spatial awareness for local retailer } \\
\text { suggestion }\end{array}$ & & & $x$ & $x$ \\
\hline $\begin{array}{l}\text { Renewables installation return } \\
\text { estimator }\end{array}$ & & $x^{12,13}$ & $x$ & $x$ \\
\hline Architectual Element Evaluation & & $x^{2,14}$ & $x$ & $x$ \\
\hline Software updates and expansions & & & $x$ & $x$ \\
\hline
\end{tabular}

Table 1. A possible feature list comparing the current audit system, existing technology and future applications to be built for smartphone (x signifies positive response, V1 means generation 1, V2 means generation 2). Legend: 1.(NRC 2007b), 2.(NRC 2009b), 3.(ecoEnergy 2009), 4.(NRC 2009c), 5. (EnergyCap 2010), 6.(Energy Star 2010a), 7.(Energy Star 2010b), 8.(MF Software 2009), 9.(Amazon 2010), 10.(Occipital 2010), 11.(Google 2010a), 12.(NRC 2010a), 13.(Solmetric Inc., 2010), 14. (ESP-R) and 15. (NRC 2009e) 


\begin{tabular}{|l|r|r|r|r|r|r|r|r|r|}
\cline { 2 - 11 } \multicolumn{1}{c|}{} & \multicolumn{3}{c|}{$\mathbf{2 0}$ years } & \multicolumn{3}{c|}{$\mathbf{3 0}$ years } & \multicolumn{3}{c|}{$\mathbf{5 0}$ Years } \\
\hline Audit Efficiency & $\mathbf{1 0 \%}$ & $\mathbf{3 0 \%}$ & $\mathbf{5 0} \%$ & $\mathbf{1 0 \%}$ & $\mathbf{3 0 \%}$ & $\mathbf{5 0 \%}$ & $\mathbf{1 0 \%}$ & $\mathbf{3 0 \%}$ & $\mathbf{5 0 \%}$ \\
\hline SM Case 1 & 40 & 121 & 202 & 160 & 480 & 800 & 402 & 1205 & 2009 \\
\hline SM Case 2 & 74 & 223 & 372 & 193 & 580 & 966 & 435 & 1305 & 2174 \\
\hline TA Case 1 & 45 & 160 & 275 & 104 & 366 & 629 & 292 & 1032 & 1771 \\
\hline TA Case 2 & 14 & 49 & 85 & 14 & 113 & 194 & 90 & 319 & 547 \\
\hline
\end{tabular}

Table 2. A sensitivity analysis of the four types of energy audits. Results are shown in $\mathrm{Mt}$ of $\mathrm{CO}_{2}$ saved, and are based on the length of time and the audit effectiveness.

Figure Captions
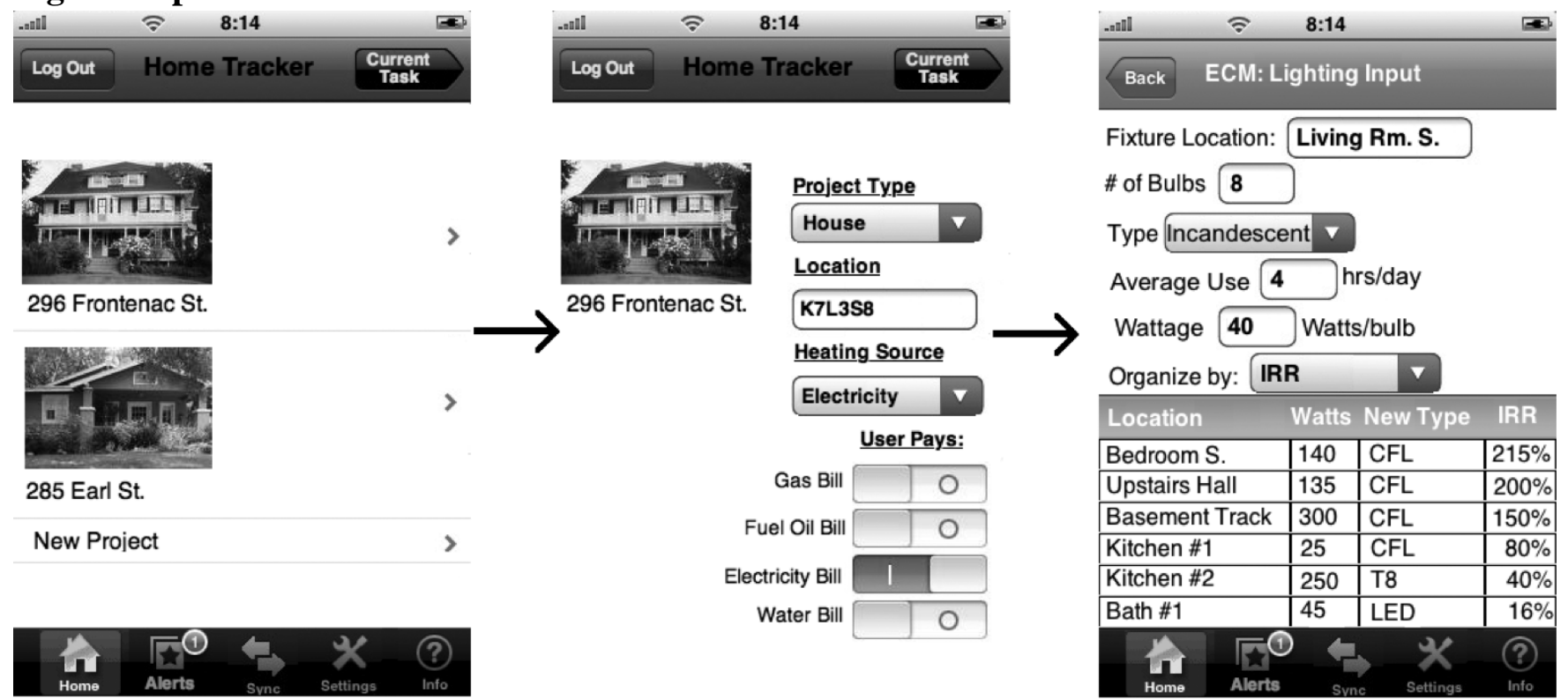

Fixture Location: Living Rm. S.

\# of Bulbs 8

Type Incandescent $\mathbf{V}$

Average Use 4 hrs/day

Wattage 40 Watts/bulb

Organize by: IRR

\begin{tabular}{|l|l|l|r|}
\hline Location & \multicolumn{3}{c}{ Watts } \\
\hline Bedroom S. & 140 & CFL & $215 \%$ \\
\hline Upstairs Hall & 135 & CFL & $200 \%$ \\
\hline Basement Track & 300 & CFL & $150 \%$ \\
\hline Kitchen \#1 & 25 & CFL & $80 \%$ \\
\hline Kitchen \#2 & 250 & T8 & $40 \%$ \\
\hline Bath \#1 & 45 & LED & $16 \%$ \\
\hline
\end{tabular}

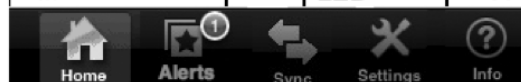

Figure 1. A simplified program outline including input/output page for a lighting fixture ECM.

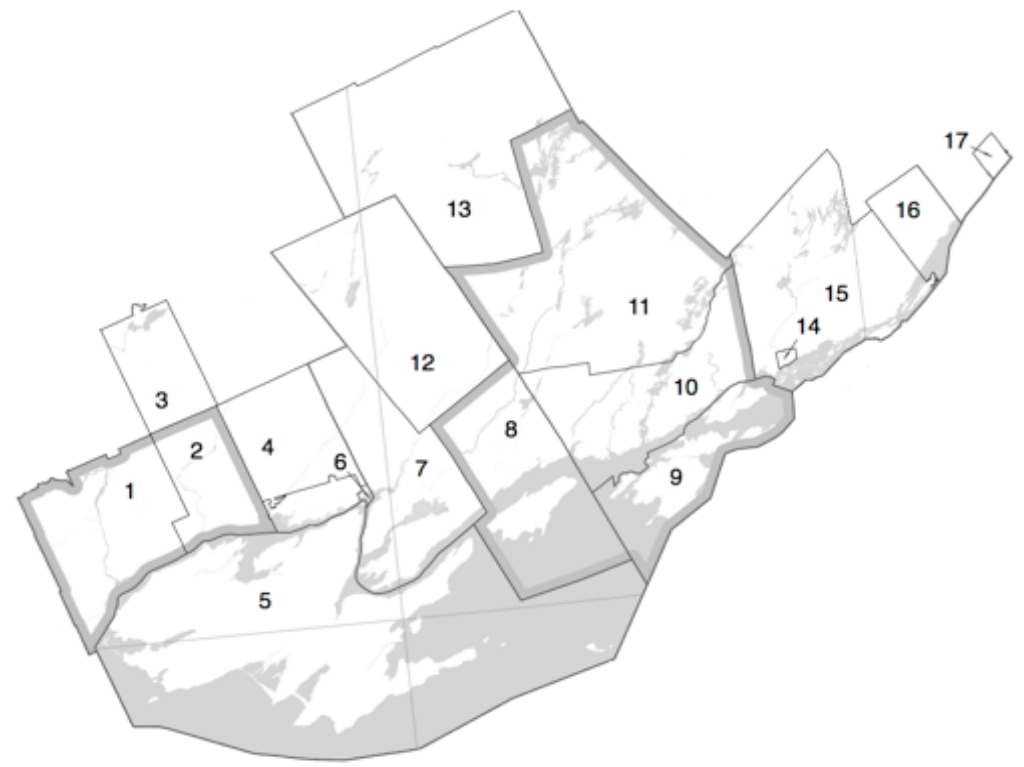

Legend

1. Quinte West, CY,

2. Belleville, CY,

3. Centre Hastings, MU,

4. Tyendinaga, TP,

5. Prince Edward, CY,

6. Deseronto, T,

7. Greater Napanee, $T$,

8. Loyalist, TP,

9. Frontenac Islands, TP,

10. Kingston, CY,

11. South Frontenac, TP,

12. Stone Mills, TP,

13. Central Frontenac, TP,

14. Gananoque, $\mathrm{T}$,

15. Leeds and the Thousand Islands, TP,

16. Front of Yonge, TP

17. Brockville, CY

Figure 2. Statistics Canada census subdivisions map for Hearthmakers Inc. territory. 
P. Leslie, J. M. Pearce, R. Harrap, S. Daniel, “The application of smartphone technology to economic and environmental analysis of building energy conservation strategies”, International Journal of Sustainable Energy 31(5), pp. 295-311 (2012). DOI: http://dx.doi.org/10.1080/1478646X.2011.578746

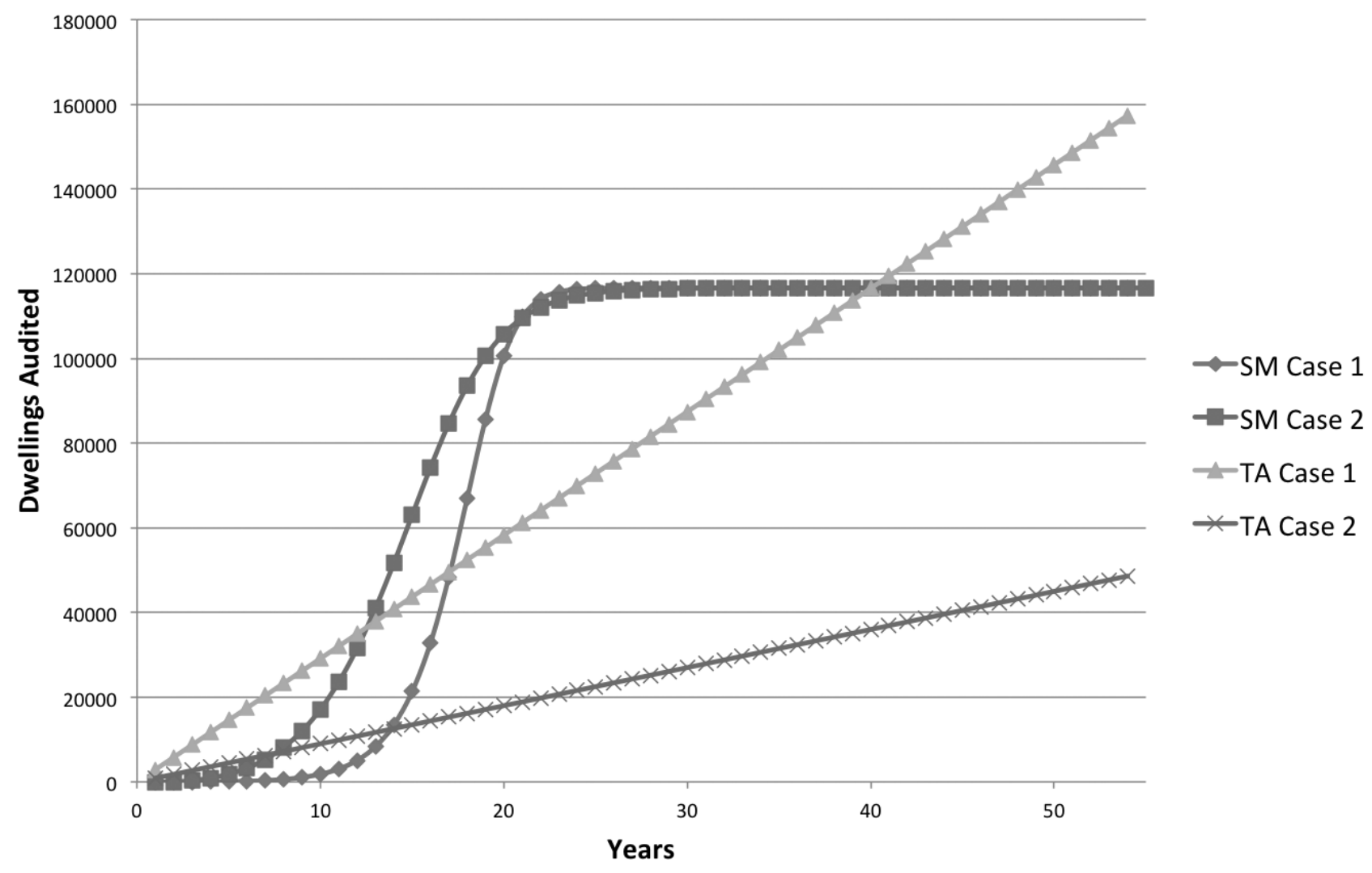

Figure 3. Cumulative audits performed of the four auditing cases including two traditional auditing scenarios and two smartphone based auditing scenarios.

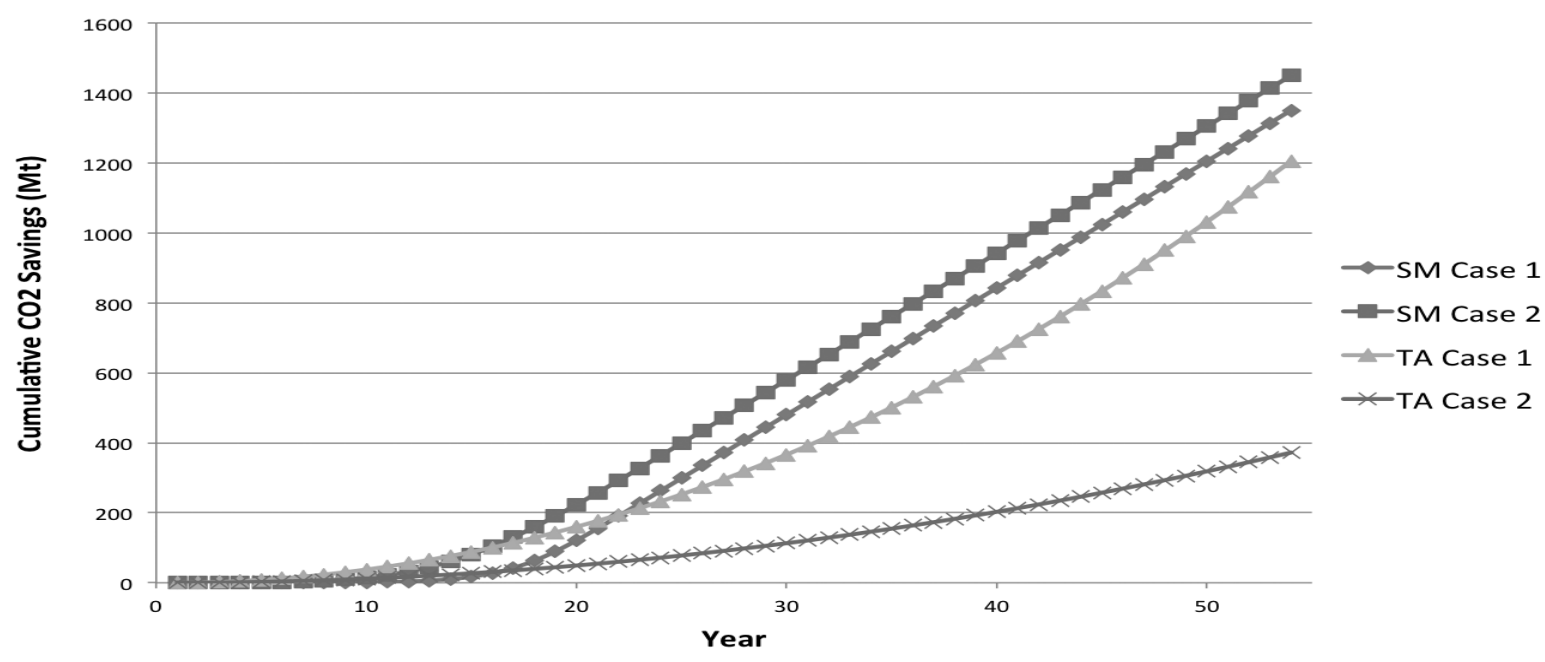

Figure 4. Cumulative $\mathrm{CO}_{2}$ savings of four auditing cases including two traditional auditing scenarios and two smartphone based auditing scenarios. Audit effectiveness was 0.30. 